\title{
TEMPERATURE-DEPENDENT DEVELOPMENT OF PARASITOIDS ON TWO SPECIES OF ARMOURED SCALE INSECTS
}

\author{
D.P. LOGAN $^{1}$ and C. THOMSON ${ }^{2,3}$ \\ ${ }^{1}$ HortResearch Te Puke, 412 No. 1 RD, Te Puke \\ ${ }^{2}$ HortResearch Ruakura, Private Bag 3123, Hamilton \\ ${ }^{3}$ Present address: 4 Sussex St, Hamilton \\ Corresponding author: dlogan@hortresearch.co.nz
}

\begin{abstract}
The duration of development of the parasitoid Encarsia citrina (Craw) (Hymenoptera: Aphelinidae) on its hosts greedy scale, Hemiberlesia rapax (Comstock), and oleander scale, Aspidiotus nerii Bouché, (Hemiptera: Diaspididae), and of Signiphora merceti (Malenotti) (Hymenoptera: Signiphoridae) on greedy scale was determined at five constant temperatures. Weibull functions were fitted to the cumulative distribution of parasitoid emergence times, and development rates for 5, 50 and 95\% emergence were calculated. Development rates for each parasitoid-scale combination were described by the same linear regression equations for $50 \%$ emergence, and for $95 \%$ emergence. Developmental threshold and thermal constant for $50 \%$ and $95 \%$ emergence of parasitoids was $10.3^{\circ} \mathrm{C}$ and $363.8 D^{\circ}$, and $10.3^{\circ} \mathrm{C}$ and $441.2 D^{\circ}$. The threshold and thermal constant for $5 \%$ emergence varied from $9.3^{\circ} \mathrm{C}$ to $12.3^{\circ} \mathrm{C}$ and $225.4 D^{o}$ to $328.2 D^{o}$. Duration of development in the field was simulated using 13 months of hourly temperatures recorded at Te Puke.
\end{abstract}

Keywords: parasitoids, armoured scale, development rate, temperature.

\section{INTRODUCTION}

Greedy scale, Hemiberlesia rapax (Comstock), and oleander scale, Aspidiotus nerii Bouché, (Hemiptera: Diaspididae), are commonly found on kiwifruit (Lo \& Blank 1989; Tomkins et al. 1992) and are quarantine pests. Both greedy and oleander scale have two generations on kiwifruit each year (Greaves et al. 1994; Blank et al. 1995, 1996). Mature females and crawlers of greedy scale are most abundant in spring and in late summerautumn on wood and leaves in the canopy of kiwifruit vines. The phenology of oleander scale is less well known but may be similar to that of greedy scale.

Two common parasitoids of diaspidid scale in orchards are Encarsia citrina (Craw) (Hymenoptera: Aphelinidae) and Signiphora merceti (Malenotti) (Hymenoptera: Signiphoridae) (Steven 1990). Both parasitoids are probably self-introduced to New Zealand (Hill 1989). Second-stage females are preferred hosts for egg-laying by E. citrina while third instars and mature scales are preferred hosts of S. merceti (Steven 1990). To further understand the ecology of diaspidid parasitoids in kiwifruit, the temperature-dependent development rate of E. citrina and S. merceti on greedy and oleander scale was studied and used to estimate duration of development in the field. These data may be used in models of the population dynamics of greedy and oleander scale (Tomkins et al. 1997; Blank et al. 2000).

\section{MATERIALS AND METHODS}

Temperature-dependent development rate

Greedy and oleander scale were reared on potatoes cv. Red Desiree at $20^{\circ} \mathrm{C}$ and a photoperiod of 16:8 h (light:dark). Parasitoids that emerged from scale insects collected 
from kiwifruit orchards were separated according to species; E. citrina was reared on oleander scale and $S$. merceti was reared on greedy scale. The development time of parasitoids was determined from oviposition to emergence at 15, 17.5, 20, 22.5 and $25^{\circ} \mathrm{C}$. Adults of $E$. citrina $(\mathrm{n}=20-25)$ were introduced to the surface of potatoes infested with second instars of either greedy or oleander scale. Potatoes with adults of greedy scale were exposed to adults of $S$. merceti. After a day at $20^{\circ} \mathrm{C}$, parasitoids were removed and 6-11 potatoes placed in constant temperature rooms with a $16: 8 \mathrm{~h}$ (light:dark) photoperiod. Scales were checked for emergence holes left by parasitoids every day or second day until no new emergence holes were observed.

The frequency distribution of parasitoid emergence times was skewed towards the longest times. To estimate days for 5,50 and 95\% of the population of each parasitoid to complete development on each scale host and emerge, a Weibull function (Wagner et al. 1984) was fitted to the data using SigmaPlot ${ }^{\circledR}$ as follows:

$$
y=1-e^{\left[-\left(\frac{x-c}{a}\right)^{b}\right]}
$$

where $a, b$ and $c$ are constants, $x$ is time in days and $y$ is the cumulative proportion of emerged adults. The Weibull function was re-arranged as:

$$
x=a^{b} \sqrt{-\ln (1-y)}+c
$$

This allowed days $(x)$ to 5, 50 and $95 \%$ emergence of the population to be calculated.

Linear regressions were determined for development rate $(D)$ on temperature, where $D=100 / d$, with $d$ being the time in days for parasitoids to complete development and emerge. The regressions of development rate at $5 \%, 50 \%$ and $95 \%$ emergence for each parasitoid-scale combination on temperature were tested for differences at a significance level of $\mathrm{P}<0.05$ using analysis of covariance (Zar 1996). Where no difference occurred, a common slope and intercept were calculated. Where differences occurred, each pair of slopes was tested for differences at $\mathrm{P}<0.05$ using the Tukey test (Zar 1996). The threshold temperature for development $\left(T_{0}\right)$ was calculated as $T_{0}=-a / b$, where $a$ is the intercept and $b$ is the slope of the linear regression equation. The sum of temperature above $T_{0}$ required for development or thermal constant $(K)$, expressed in day degrees $\left(D^{o}\right)$ was calculated as $K=d\left(T-T_{0}\right)$, where $T$ is any temperature higher than $T_{0}$ and $d$ is duration of development in days at temperature $T$.

\section{Simulated development in the field}

A 13-month series of air temperatures recorded hourly at Te Puke, Bay of Plenty, was used to estimate duration of parasitoid development in the field. Fractions of $D^{o}$ were summed hourly as follows:

$$
K=\sum_{t_{o}}^{t_{e}}\left[\sum_{h=1}^{24} \frac{T_{h}-T_{0}}{24}\right]
$$

The variables $t_{o}$ and $t_{e}$ are time at oviposition and time at emergence, respectively, $T_{h}$ is hourly air temperature at Te Puke and $T_{0}$ is the threshold temperature for development, until $K$ was reached. If $T-T_{0} \leq 0$ then $D^{o}=0$. The number of $D^{o}$ required to complete development was summed starting at 1 a.m. every week from 1 January until 24 December 2001. Duration of development was simulated for 5, 50 and 95\% emergence of each parasitoid species on its host(s).

\section{RESULTS}

Temperature-dependent development rate

Parasitoids were successfully reared at all temperatures. Development of E. citrina on greedy scale and oleander scale was determined for 316 and 3316 individuals respectively. Development of $S$. merceti on greedy scale was determined for 432 individuals. Development times at different temperatures for $E$. citrina on greedy scale, E. citrina on oleander scale and $S$. merceti on greedy scale were in the range 20 to 76 
days, 22 to 146 days and 20 to 108 days respectively (Fig. 1). Adjusted $\mathrm{r}^{2}$ values for the Weibull function fitted to data for cumulative emergence of parasitoids were in the range 0.97 to 0.99 (Fig. 1). Days to emergence of parasitoids, calculated from fitted Weibull functions, tended to increase with cooler temperature and varied most for each parasitoidscale combination at $15^{\circ} \mathrm{C}$ (Table 1$)$.
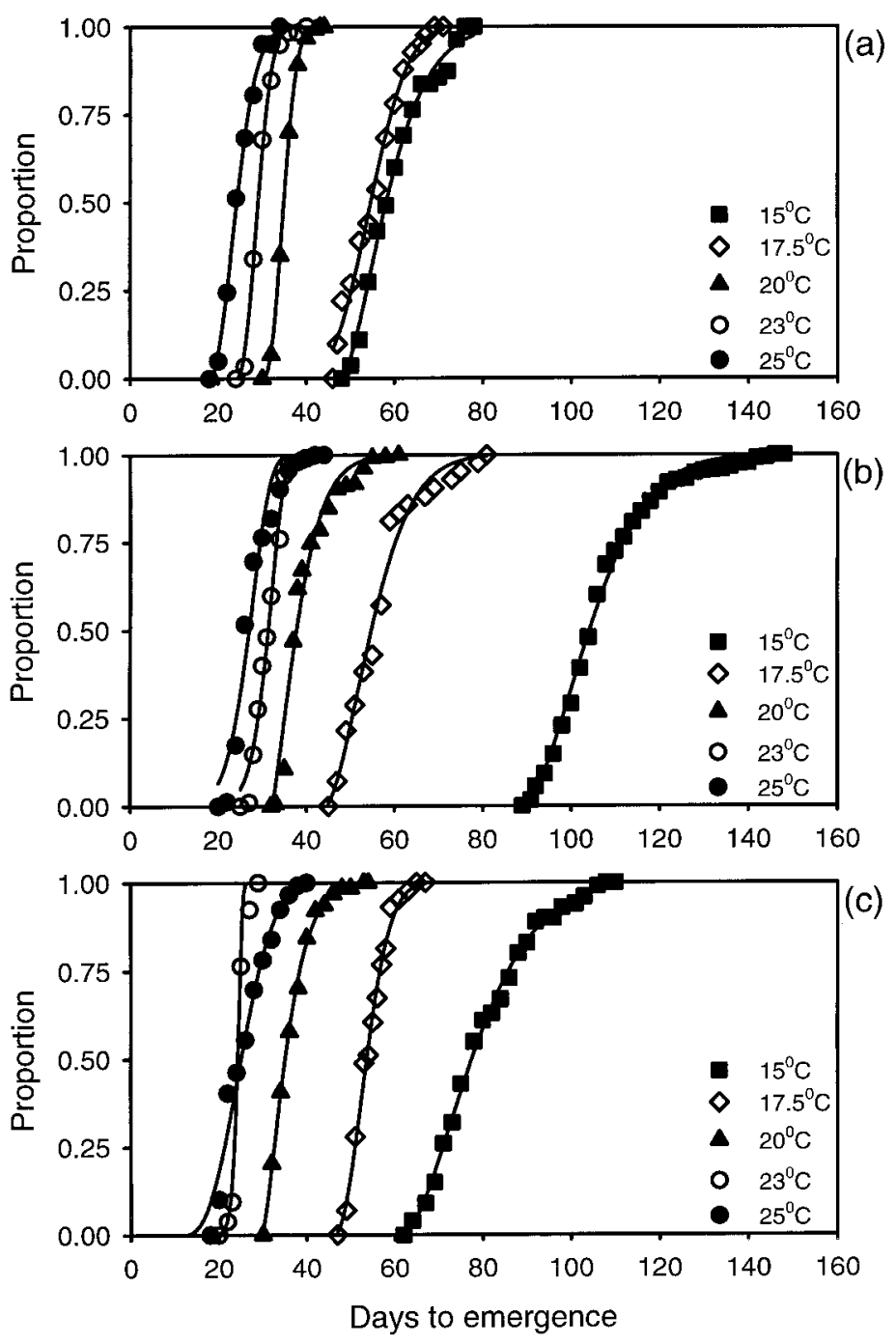

FIGURE 1: Cumulative proportion of parasitoids emerging from diaspidid scale hosts at 5 constant temperature regimes (symbols) and fitted Weibull functions (lines). (a) E. citrina on greedy scale; (b) E. citrina on oleander scale; (c) $S$. merceti on greedy scale. 
TABLE 1: Days to 5,50 and $95 \%$ emergence of the parasitoid $E$. citrina on greedy scale and oleander scale, and of the parasitoid $S$. merceti on greedy scale calculated from Weibull functions fitted to data for cumulative emergence at five constant temperatures.

\begin{tabular}{|c|c|c|c|c|c|c|c|c|c|}
\hline \multirow[t]{2}{*}{$\begin{array}{l}\text { Temp } \\
{ }^{\circ} \mathrm{C}\end{array}$} & \multicolumn{3}{|c|}{$\begin{array}{l}\text { E. citrina } \mathrm{x} \text { greedy } \\
\text { scale }\end{array}$} & \multicolumn{3}{|c|}{$\begin{array}{l}\text { E. citrina } \mathrm{x} \text { oleander } \\
\text { scale }\end{array}$} & \multicolumn{3}{|c|}{$\begin{array}{l}\text { S. merceti } \mathrm{x} \text { greedy } \\
\text { scale }\end{array}$} \\
\hline & $5 \%$ & $50 \%$ & $95 \%$ & $5 \%$ & $50 \%$ & $95 \%$ & $5 \%$ & $50 \%$ & $95 \%$ \\
\hline 15 & 49.8 & 58.1 & 74.2 & 92.4 & 104.3 & 125.0 & 65.0 & 77.5 & 100.5 \\
\hline 17.5 & 44.6 & 54.6 & 65.9 & 46.4 & 54.8 & 69.7 & 48.2 & 53.6 & 61.4 \\
\hline 20 & 31.7 & 34.9 & 38.9 & 32.9 & 37.8 & 48.5 & 30.5 & 35.0 & 44.5 \\
\hline 23 & 25.6 & 29.0 & 33.4 & 25.1 & 31.3 & 35.5 & 22.0 & 24.3 & 25.6 \\
\hline 25 & 19.7 & 24.2 & 30.9 & 19.3 & 27.0 & 32.6 & 16.7 & 25.0 & 35.0 \\
\hline
\end{tabular}

Development rate was influenced by temperature for each parasitoid-scale combination $(\mathrm{P}<0.05)$, except for $95 \%$ emergence of S. merceti on greedy scale (Table 2). Slopes and intercepts of regression lines fitted to 50\% emergence and to $95 \%$ emergence of parasitoids on temperature did not differ for each parasitoid-scale combination $(\mathrm{P}>0.05)$ and common linear regressions were calculated (Table 2). Slopes of the regression lines fitted to 5\% emergence differed $(\mathrm{P}<0.05)$; the slope for $S$. merceti on greedy scale $(0.44)$ differed from the slope for E. citrina on greedy scale (0.30).

TABLE 2: Linear regression equations of development rate on temperature, threshold temperatures for development $\left(T_{0}\right)$ and thermal constants $(\mathrm{K})$ for 5,50 and $95 \%$ emergence of the parasitoid $E$. citrina on greedy scale and oleander scale, and of the parasitoid $S$. merceti on greedy scale, and for combined data for parasitoid-scale combinations.

\begin{tabular}{|c|c|c|c|c|c|c|}
\hline \multirow{2}{*}{$\begin{array}{l}\text { Parasitoid x scale } \\
\text { combination }\end{array}$} & \multirow{2}{*}{$\begin{array}{c}\% \text { parasitoids } \\
\text { emerged }\end{array}$} & \multicolumn{3}{|c|}{ Linear regression } & \multirow{2}{*}{$\begin{array}{c}\mathrm{T}_{0} \\
\left({ }^{\circ} \mathrm{C}\right)\end{array}$} & \multirow{2}{*}{$\begin{array}{c}\mathrm{K} \\
\left(D^{o}\right)\end{array}$} \\
\hline & & Equation & $\mathrm{R}^{2}$ & $\mathrm{P}$ & & \\
\hline \multirow{3}{*}{$\begin{array}{l}\text { E. citrina } \mathrm{x} \text { greedy } \\
\text { scale }\end{array}$} & 5 & $y=0.30 x-2.84$ & 0.95 & $<0.01$ & 9.3 & 328.2 \\
\hline & 50 & $y=0.25 x-2.27$ & 0.96 & $<0.01$ & 9.0 & 396.7 \\
\hline & 95 & $y=0.21 x-1.81$ & 0.94 & $<0.01$ & 8.8 & 484.8 \\
\hline \multirow{3}{*}{$\begin{array}{l}\text { E. citrina } \mathrm{x} \\
\text { oleander scale }\end{array}$} & 5 & $y=0.39 x-4.78$ & 0.99 & $<0.01$ & 12.2 & 255.5 \\
\hline & 50 & $y=0.27 x-2.93$ & 0.98 & $<0.01$ & 10.9 & 372.7 \\
\hline & 95 & $y=0.23 x-2.64$ & 0.99 & $<0.01$ & 11.4 & 459.8 \\
\hline \multirow{3}{*}{$\begin{array}{l}\text { S. merceti x greedy } \\
\text { scale }\end{array}$} & 5 & $y=0.44 x-5.44$ & 0.97 & $<0.01$ & 12.3 & 225.4 \\
\hline & 50 & $y=0.30 x-3.28$ & 0.95 & $<0.01$ & 10.8 & 329.1 \\
\hline & 95 & $y=0.24 x-2.53$ & 0.76 & 0.06 & 10.5 & 413.8 \\
\hline \multirow[t]{3}{*}{ Combined data } & 5 & - & - & - & - & - \\
\hline & 50 & $y=0.27 x-2.82$ & 0.93 & $<0.01$ & 10.3 & 363.8 \\
\hline & 95 & $y=0.23 x-2.33$ & 0.85 & $<0.01$ & 10.3 & 441.2 \\
\hline
\end{tabular}

Simulated development in the field

Simulated development of time to 50 and to $95 \%$ emergence of parasitoids in the field at Te Puke (Fig. 2) was based on threshold temperatures and thermal constants calculated from common regressions (Table 2). Threshold temperatures and thermal constants for each parasitoid-scale combination were used to simulate time to $5 \%$ emergence (Fig. 2). Fastest development was 32.8 days for eggs laid in late January, and slowest development was 194.3 days for eggs laid in mid-April (Fig. 2). The largest difference in development time from 5 to $95 \%$ emergence was for eggs laid in 
mid-March (125 days). The maximum and minimum temperatures in the data set were $-1.48^{\circ} \mathrm{C}$ and $28.36^{\circ} \mathrm{C}$, respectively, with $24 \%$ of temperatures being below the threshold of $10.3^{\circ} \mathrm{C}$.

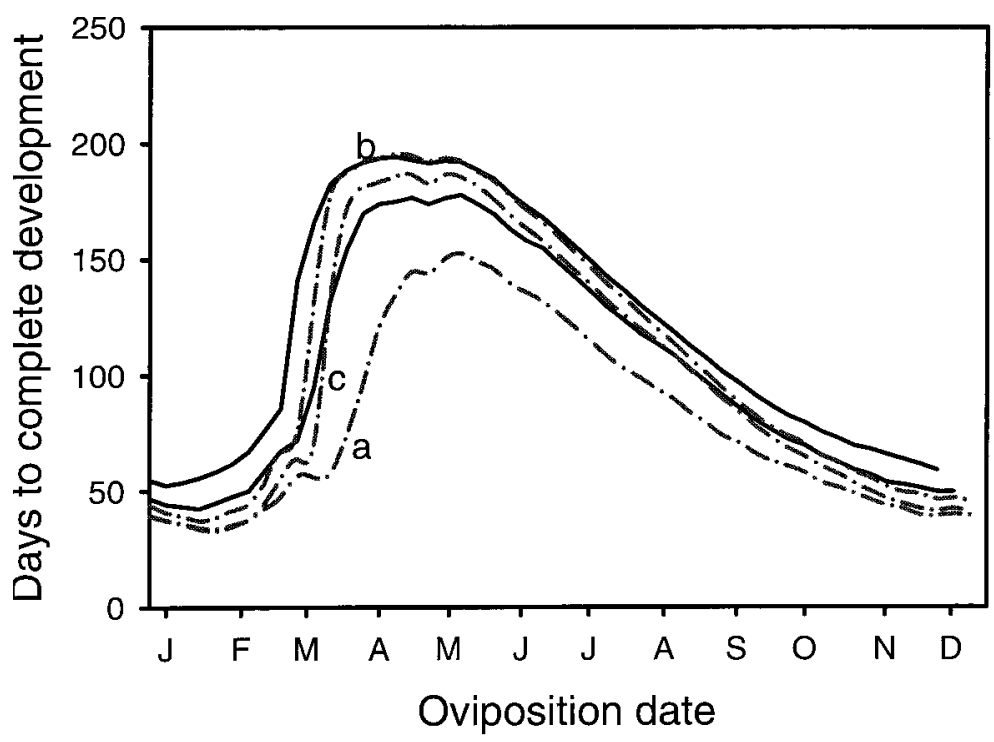

FIGURE 2: Simulated time in days for parasitoids to emerge from scale hosts in the field at Te Puke, Bay of Plenty. Solid lines are simulated times for 50 and $95 \%$ emergence based on thermal constants and threshold temperatures for common regressions. Dashed lines are for $5 \%$ emergence of parasitoids based on thermal constants and threshold temperatures for regressions of each parasitoid-scale combination. (a) E. citrina on greedy scale; (b) E. citrina on oleander scale; (c) $S$. merceti on greedy scale.

\section{DISCUSSION}

Development rate to $50 \%$ and to $95 \%$ emergence of parasitoids was the same for each parasitoid-scale combination. This was unexpected as the parasitoids belong to different families and attack different stages of their scale-insect hosts. An implication is that the host plant used for rearing greedy and oleander scale in this study (potato) may have influenced development rate of parasitoids by affecting the nutritional value of scale insects as hosts. Nutrition is known to influence development in some insects (Gould \& Elkington 1990; Ali \& Gaylor 1992). Temperature-dependent development rates determined in this study need to be validated in the field or at least under experimental conditions more closely resembling the field before they can be used with confidence in a scale-parasitoid model.

Assuming a maximum period of one week between emergence and oviposition by parasitoids (C. Thomson, unpubl. data), four or five generations per year are possible at Te Puke. The linear-above-threshold model used in this study, underestimates development rate at low temperature extremes because development rate tends to flatten out and approach the temperature at which no development occurs asymptotically. The 
development time of parasitoids may be faster during autumn and winter than suggested by simulations in this study and there may be more than four or five generations per year. In comparison, there are only two generations of scale per year. A short development time relative to hosts is considered a desirable attribute of parasitoids, but is only one of the characteristics of successful biological control agents (Kidd \& Jervis 1996).

Little is known about how the parasitoids E. citrina and S. merceti affect the abundance of diaspidid scales in kiwifruit orchards. Numbers of parasitoids increased following two generations of increasing abundance of greedy scale on the native plant taraire (Beilschmiedia tarairi) (Blank et al. 1995). Sampling was discontinued before it was possible to determine whether parasitism reduced scale populations in later generations. Parasitism of greedy scale in unsprayed kiwifruit orchards can be as high as $90 \%$, but varies widely (Hill 1989). The cause of variation in parasitism rates of greedy and oleander scale is poorly understood and may be partly due to asynchrony in phenology between parasitioids and their scale hosts. Including our data for parasitoid development rates in population models of greedy and oleander scale may lead to a further understanding of the limits to biological control of scale in kiwifruit orchards.

\section{ACKNOWLEDGEMENTS}

Derrick Wilson assisted Cheryl Thomson during the experimental work and Phil Allison organised the raw data. Garry Hill and John Charles made useful changes to the draft manuscript. Funding for this research was provided by the Foundation for Research, Science and Technology.

\section{REFERENCES}

Ali, A.; Gaylor, M.J. 1992: Effects of temperature and larval diet on the development of the beet armyworm (Lepidoptera: Noctuidae). Environ. Entomol. 21: 780-786.

Blank, R.H.; Gill, G.S.C.; Olson, M.H. 1995: Seasonal abundance of greedy scale (Homoptera: Diaspididae) and associated parasitoids of taraire (Beilschmiedia tarairi). J. Econ. Entomol. 88: 1634-1640.

Blank, R.H.; Gill, G.S.C.; Upsdell, M.P. 1996: Greedy scale, Hemiberlesia rapax (Hemiptera: Diaspididae), phenology on kiwifruit leaves and wood. N.Z. J. Crop Hort. Sci. 24: 239-248.

Blank, R.H.; Gill, G.S.C.; Kelly, J.M. 2000: Development and mortality of greedy scale (Homoptera: Diaspididae) at constant temperatures. Environ. Entomol. 29: 934942.

Gould, J.R.; Elkington, J.S. 1990: Temperature-dependent growth of Cotesia melanoscela (Hymenoptera: Braconidae), a parasitoid of the gypsy moth (Lepidoptera: Lymantriidae). Environ. Entomol. 19: 859-865.

Greaves, A.J.; Davys J.W.; Dow, B.W.; Tomkins, A.R.; Thomson, C.; Wilson, D.J. 1994: Seasonal temperatures and the phenology of greedy scale populations (Homoptera: Diaspididae) on kiwifruit vines in New Zealand. N.Z. J. Crop Hort. Sci. 22: 7-16.

Hill, M.G. 1989: Diaspididae, armoured scales. In: Cameron, P.J.; Hill, R.L.; Bain, J.; Thomas, W.P. ed. A review of biological control of insect pests and weeds in New Zealand 1874 to 1987. Tech. Comm. CAB Int. Inst. Biol. Control 10. CAB, Wallingford, U.K. Pp. 177-182.

Kidd, N.A.C.; Jervis, M.A. 1996: Population dynamics. In: Jervis, M.; Kidd, N. ed. Insect natural enemies. Practical approaches to their study and evaluation. Chapman \& Hall, London. Pp. 293-374.

Lo, P.L.; Blank, R.H. 1989: A survey of armoured scale species (Hemiptera: Diaspididae) in kiwifruit orchards. N.Z. Entomol. 12: 1-4.

Steven, D. 1990: Entomology and kiwifruit. In: Warrington, I.J.; Weston, G.C. ed. Kiwifruit: Science and Management. Ray Richards Publisher, Auckland. Pp. 362412. 
Tomkins, A.R.; Thomson, C.; Wilson, D.J.; Greaves, A.J. 1992: Armored scale insects on unsprayed kiwifruit vines in the Waikato. N.Z. Entomol. 15: 58-63.

Tomkins, A.R.; Allison, P.A.; Thomson, C.; Wilson, D.J. 1997: Development of a model to predict the phenology of oleander scale (Aspidiotus nerii) infesting kiwifruit. Acta Hort. 444: 791-795.

Wagner, T.L.; Hsin-I, W.; Sharpe, P.J.H.; Coulson, R.N. 1984: Modeling distributions of insect development time: A literature review and application of the Weibull function. Ann. Entomol. Soc. Am. 77: 475-487.

Zar, J.H. 1996: Biostatistical Analysis. Prentice Hall, Upper Saddle River, New Jersey. $662 \mathrm{p}$. 